\title{
Analysis to Select Filter Media and The Treatment Effect of Non-point Pollution Source in Road Runoff
}

\author{
Lee, Tae Goo ${ }^{*}$ Han, Young Hae* \\ * Semyung University, Depart. of Architecture Engineering, Jecheon-City Chungbuk, South Korea (tg_lee@semyung.ac.kr) \\ ** Corresponding author, Eco-Arche Institute of Ecological Urban Design \& Architecture, Jecheon-City Chungbuk, South Korea (youngseahan@nate.com)
}

\section{A B STR A C T}

This study selected and analyzed filter media that can be applied in non-point pollution reduction devices aimed at processing the source of pollution on site for road runoff that increases rapidly in rainfall-runoff in order to improve the water quality of urban areas.

First, the factors that affect the quality of runoff caused by sources of non-point pollution include physical and social factors such as the usage of land around the area of water collection, type of pavement and movement of cars and people, as well as rainfall characteristics such as frequency, intensity, amount and duration of rainfall.

Second, the purification tests of the filter media were processed for $\mathrm{pH}, \mathrm{BOD}, \mathrm{COD}$ and $\mathrm{T}-\mathrm{P}$, and the filter media showed to have initial purification effect at that items. However, the filter media showed to be very effective for the processing of SS, T-N, Zn and Cd from the beginning to the end.

Third, for filter media, zeolite and vermiculite showed to be effective for processing SS, T-N, Zn and CD constantly, and composite filter media including zeolite showed to have strong processing effects.

The authors conclude that this study can be applied to technical areas and policies aimed at reducing non-point pollution in urban areas and can also contribute to allowing eco-friendly management of rainfall as well as improvement of water quality.

\section{KEYW ORD}

non-point pollution

filter media

first-flush,

road runoff

non-point pollution reduction devices

\section{A C CEPTA N CE IN FO}

Received March 17, 2014

Final revision received May 7, 2014

Accepted May 12, 2014

\section{Introduction}

\subsection{Background and Objective of the Study}

As urban areas have recently been applied with decentralized rainwater management facility that can slow down the flow rate of rainfall runoff, it is necessary to have a process that removes or slows down the pollution sources of rainwater runoff that penetrates the areas.

However, the management of non-point pollution sources is difficult due to the intermittence of rainfall runoff, wide discharging scope, different pollution sources and diversity of load. Accordingly, it is not enough to apply a single method to collect and treat rainfall effluent. Instead, it is more effective to use both physical and non-physical technique ${ }^{1)}$.

Among the physical control methods, installable non-point pollution reduction device is a plausible treatment facility for initial rainfall runoff that has intensive pollution concentration and so installing it at the starting point of rainfall runoff is effective to reduce non-point pollution. In case that rainfall causes runoff and the rainwater runoff flows into waste

pISSN 2288-968X, eISSN 2288-9698 http://dx.doi.org/10.12813/kieae.2014.14.3.05

(c) 2014 KIEAE Journa

water/sewage treatment terminals through urban drain pipes, it can increase the cost of treatment and decrease the efficiency of treatment.

The water quality of rainfall runoff is affected by physical and social factors such as usage of land, type of load pavement and traffic and population in a concerned area where it is collected. The water quality is different even under the same usage of land due to the different conditions of rainfall such as frequency, intensity and duration of rainfall.

In this respect, it is necessary to develop non-point pollution reduction device that can treat the pollution sources of road runoff, which occurs at a rapid rate when it rains in urban areas, to improve the water quality of urban areas. Accordingly, it also needed to develop filter media to reduce the pollution sources by characteristic of the runoff.

Therefore, the present study aims to select filter media and analyze the effectiveness of the media that can be installed in the filters of a reduction unit. This study expects that the results of such effort can be utilized for the policies and technological

1) Physical technique means a method to treat pollutants physically and chemically, using vegetation, precipitation and filtration while non-physical technique includes a method to solve non-point pollution problems by using legal regulations of land development and use and one to control generating source in order to prevent the accumulation of pollutants and them from being washed down during rainfall (Lee Young Gil, 2007). 
sectors of non-point pollution reduction for urban areas and contribute to improving water environment and the management of environment-friendly rainwater management.

\subsection{Research Method}

This study was performed in the following ways.

First, the precedent studies related to non-point pollution sources was reviewed to know the characteristics of road surface runoff and the tendency of runoff by pollution source. This attempt was made to set the type of non-point pollution reduction device fit to land usage and the features of the surface of the runoff and choose suitable filter media.

Second, an analysis was carried out on filter media to select that can be applied to non-point pollution treatment device. A variety of media were experimented and analyzed for the level of purification by filter media. Of them, single filter media was first chosen and analyzed for its purification and the results of the experiment was used to test the purification level of compound filter media, which are combined with two highly efficient single media at one-to-one ratio. The results of the test were employed in selecting a suitable filter media for pollution sources.

\section{Precedent Studies}

The precedent studies of non-point pollution source are concentrated mainly on the analysis of the runoff characteristics of pollution materials using modeling (Hwang Soo Young, 2008; Son Jang Won ,2009) and the characteristics of the water quality of road runoff using on-spot monitoring(Oh Jae Il et al., 2005; Go Sung Hun et al., 2009; Park Sang Woo et al., 2007, etc.). Also, they focus on the planning side of non-point pollution reduction device such as the treatment efficiency (Choi Sung Kyu, 2013; Lee, Byung Soo, 2008) and the designing criteria of non-point pollution reduction device(Kim Hee Jin, 2010; Lee Young Gil,
2007). According to the findings of the study on the characteristics of road runoff using a filed monitoring, most of $\mathrm{COD}_{\mathrm{Cr}}, \mathrm{BOD}_{5}$, and TN among pollutants run off after about $20 \%$ of runoff time passes and pollution load sharply decreases after that. On the contrary, TP and SS tend to run off persistently (Oh Jae Il et al.).

The study regarding land use and the treatment efficiency of a facility, which need to be considered for application to non-point pollution reduction devices, show the following results of research. Water quality wasn't significantly different by macroscopic division of land use (residential, commercial, industrial, automotive road). However, it was turned out that automotive road had the highest level of SS and commercial area had the highest TN concentration in effluent. It is because many dining facilities surround a commercial area and as a result food wastes are more produced in the area. Heavy metals such as Zn, $\mathrm{Cd}, \mathrm{Pb}$ and $\mathrm{Cu}$ turned out to be relatively high in automotive road and parking lot (Yoon Young Sik, 2009).

On the other hand, the study that examined the effect of an installable non-point pollution reduction device developed and applied to improve water quality water demonstrated the following results. Although the study limited water collection area to elementary school, it analyzed the characteristics of water quality of initial rainfall by the property of ground surface. To carry out the experiment, the study developed initial rainfall treatment device and combined FFM (Fiber filter mat) and PE (foamed polypropylene) filter media to choose to be applied to the device. The device was performed to measure $\mathrm{pH}$, conductivity, turbidity, color, $\mathrm{Fe}, \mathrm{Cu}, \mathrm{Zn}, \mathrm{Al}, \mathrm{TN}, \mathrm{TP}, \mathrm{NO} 3-\mathrm{N}$, NH3-N, normal bacterial treatment (Lee Jeong Hun, 2006). The study found that search results show that turbidity was highest in the road runoff from waysides and parking lot. It turns out that it was affected by frequency, intensity, amount and duration of rainfall, pavement conditions, and movement of vehicles and

Table 1. Characteristics of the urban runoff water quality

\begin{tabular}{|c|c|c|c|c|c|c|c|c|c|c|c|}
\hline Land use & BOD & COD & TSS & TDS & $\mathrm{TP}$ & TKN & $\begin{array}{l}\mathrm{NO}_{2} / \\
\mathrm{NO}_{3}\end{array}$ & $\mathrm{~Pb}$ & $\mathrm{Cu}$ & $\mathrm{Zn}$ & $\mathrm{Cd}$ \\
\hline forest & 3 & 27 & 51 & 415 & 0.11 & 0.94 & 0.80 & 0 & 0 & 0 & 0 \\
\hline urban & 3 & 27 & 51 & 415 & 0.11 & 0.94 & 0.80 & 0.014 & 0 & 0.040 & 0.001 \\
\hline farmland & 3 & 53 & 145 & 415 & 0.374 & 1.92 & 1.06 & 0 & 0 & 0 & 0 \\
\hline $\begin{array}{c}\text { residence } \\
\text {-low density }\end{array}$ & 38 & 124 & 70 & 144 & 0.52 & 3.32 & 1.83 & 0.057 & 0.026 & 0.161 & 0.004 \\
\hline $\begin{array}{c}\text { residence } \\
\text {-medium density }\end{array}$ & 38 & 124 & 70 & 144 & 0.52 & 3.32 & 1.83 & 0.180 & 0.047 & 0.176 & 0.004 \\
\hline $\begin{array}{c}\text { residence } \\
\text {-high density }\end{array}$ & 15 & 79 & 97 & 189 & 0.24 & 1.17 & 2.12 & 0.041 & 0.033 & 0.218 & 0.003 \\
\hline commercial area & 21 & 80 & 77 & 294 & 0.33 & 1.74 & 1.23 & 0.049 & 0.037 & 0.156 & 0.003 \\
\hline industrial area & 24 & 85 & 149 & 202 & 0.32 & 2.08 & 1.89 & 0.072 & 0.058 & 0.671 & 0.005 \\
\hline road & 24 & 103 & 141 & 294 & 0.43 & 1.82 & 0.83 & 0.049 & 0.037 & 0.158 & 0.003 \\
\hline water space & 4 & 6 & 6 & 12 & 0.08 & 0.79 & 0.59 & 0.011 & 0.007 & 0.003 & 0.001 \\
\hline
\end{tabular}

source; International Erosion Control Association, 2002. StormwaterQuality specialist Review 
population.

TP, TN turned out 3 to 4 times higher in the runoff of green surface than directly collected rainwater. It is mainly attributed to fertilizer components that run off from green surface. As such, the water quality was significantly different by non-point pollution according to the property of surface, even for the same land use such as elementary school. It implies that it is necessary to select right filter media suitable for those factors.

Therefore, when a filter media is selected for a non-point pollution reduction device section, it is needed to consider land usage and the conditions of ground surface, learning the results of the precedent studies. In addition, it is desirable to understand the characteristics of a concerned area runoff where the device is installed, select a filter media that highly functions for specific pollutants and analyze the effect of runoff treatment.

\section{Materials}

\subsection{Artificial Rainwater Samples}

The sediments on road surface collected by a garbage truck of outer roads in Jecheon City were used as samples. The collected sediments $(2.5 \mathrm{~kg})$ were put in a container with distilled water $(50$ liter) and stirred for a hour. After 10 minutes of settlement, the top water was used for the samples. The samples were then injected with $600 \mathrm{ml}$ of excreta, $500 \mathrm{ml}$ of $\mathrm{KH}_{2} \mathrm{PO}_{4}$ (100ppm) and $300 \mathrm{ml}$ of $\mathrm{ZnSO}_{4}(1000 \mathrm{ppm})$ and $\mathrm{Cd}\left(\mathrm{NO}_{3}\right)_{2}$ (1000ppm), respectively.

\subsection{The Selection of Filter Media}

The filter media used for the installable device can be divided into those for biological filtration method such as gravel or porous glass and those for physical adsorption method using microporous materials such as zeolite, anthracite, vermiculite, etc (Industry-Academic Cooperation Foundation of Semyeong

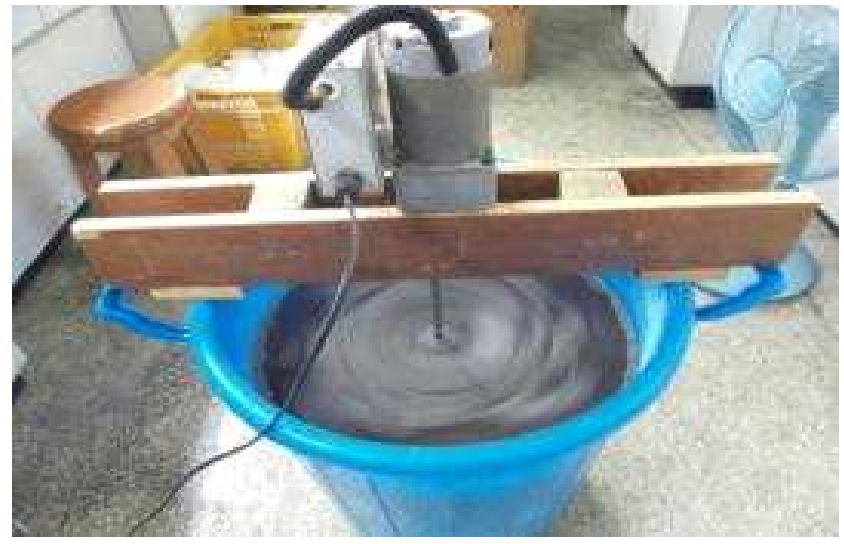

Fig 1. Production of artificial runoff water samples

University, 2013). The filtration effect and ease of maintenance of each filter media are shown in Table 2 below.

According to the review of the previous studies on the filter media generally used for the installable device, it turned out that sand, gravel, activated carbon, zeolite, anthracite and porous glass have mainly been employed. The selection criteria used for filter media filtering effect, production and supply, economic effectiveness and maintenance and management of filter media.

Based on the results of the analysis, activated carbon, zeolite, anthracite and vermiculite were selected. They were sub-divided by particle size. In addition, since each of those filter media contains fine dust and other impurities, which are generated during manufacturing process, they were cleaned with distilled water several times and charged in the filtering device. And then distilled water was injected into the lower part of it due to the consideration of unscreened matters and overflowed until turbidity reduced before experiment.

\subsection{Test Method}

The fabricated rainfall samples were stirred for 5 minutes for uniform concentration and then injected into an up-flow

Table 2. Types and characteristics of media

\begin{tabular}{|c|c|c|c|c|c|c|}
\hline & Activated carbon & Zeolite & gravel & porous glass & anthracite & vermiculite \\
\hline $\begin{array}{l}\text { filtration } \\
\text { method }\end{array}$ & $\begin{array}{l}\text { physical adsorption by } \\
\text { micropores }\end{array}$ & $\begin{array}{l}\text { Chemical ion } \\
\text { substitution method \& } \\
\text { Micropores by } \\
\text { physical adsorption }\end{array}$ & $\begin{array}{l}\text { Gravel contact } \\
\text { oxidation method } \\
\text { \& Biological } \\
\text { filtration }\end{array}$ & $\begin{array}{l}\text { physical adsorption } \\
\text { by micropores, } \\
\text { Biological filtration }\end{array}$ & $\begin{array}{l}\text { Multi-layer } \\
\text { filtration }\end{array}$ & $\begin{array}{l}\text { Multi-layer } \\
\text { filtration }\end{array}$ \\
\hline filtering effect & $\begin{array}{l}\text { Adsorption, } \\
\text { decolorization, } \\
\text { deodorization, } \\
\text { recovery }\end{array}$ & $\begin{array}{l}\text { Removal of heavy } \\
\text { metals }\end{array}$ & $\begin{array}{l}\text { Organic matter } \\
\text { decomposition } \\
\text { Decomposition of } \\
\text { sludge generated by } \\
\text { microbial }\end{array}$ & $\begin{array}{l}\text { Adsorbing and } \\
\text { deodorizing } \\
\text { \& degradation of } \\
\text { sludge }\end{array}$ & $\begin{array}{l}\text { Remove of } \\
\text { turbidity. effect of } \\
\text { removing algae, } \\
\text { water quality } \\
\text { improvement }\end{array}$ & $\begin{array}{l}\text { Removal of heavy } \\
\text { metals }\end{array}$ \\
\hline price & high & relatively cheap & relatively cheap & relatively high & relatively cheap & relatively high \\
\hline maintenance & $\begin{array}{l}\text { initial effect is } \\
\text { excellent } \\
\text { High frequency of } \\
\text { exchange }\end{array}$ & $\begin{array}{l}\text { initial effect is } \\
\text { excellent } \\
\text { easy of maintenance }\end{array}$ & $\begin{array}{l}\text { Should be cleaned or } \\
\text { replaced frequently }\end{array}$ & $\begin{array}{l}\text { Ease of Maintenance } \\
\text { Possible long-term } \\
\text { use }\end{array}$ & $\begin{array}{l}\text { filter lasts a long } \\
\text { time } \\
\text { Permanently } \\
\text { available }\end{array}$ & $\begin{array}{l}\text { filter lasts a long } \\
\text { time } \\
\text { Permanently } \\
\text { available }\end{array}$ \\
\hline
\end{tabular}


filtration device at inflow rate of $600 \mathrm{ml} / \mathrm{min}$. using a volumetric pump. "0" minute was set as the concentration before filtration and initial runoff point and the level of pollution was measured every 20 minutes (see Figure 3 and 4).

The water was collected every 20 minutes from the initial runoff to measure 8 items including $\mathrm{pH}, \mathrm{BOD}_{5}, \mathrm{COD}_{\mathrm{Mn}}, \mathrm{SS}, \mathrm{TN}$, $\mathrm{TP}, \mathrm{Zn}, \mathrm{Cd}$. pH was measured with $\mathrm{pH}$ meter and the remaining items were analyzed by the process test method of water pollution. Experiment had been carried out from March 15th to April 20th , 2013 and each test item was tested twice with selected filter media. Among the analytical values, only those that had continuous flow of test and analysis values were adopted.

Table 3. Methods of water quality measurement

\begin{tabular}{c|c|c|c}
\hline items & Measurement & items & Measurement2) \\
\hline $\mathrm{pH}$ & $\mathrm{pH}$ meter & $\mathrm{T}-\mathrm{N}$ & Absorptiometry \\
\hline $\mathrm{SS}$ & Glass fiber filter paper & $\mathrm{T}-\mathrm{P}$ & $\begin{array}{c}\text { Absorptiometry(Ascorbic } \\
\text { Acid reductionism ) }\end{array}$ \\
\hline BOD5 & $20^{\circ} \mathrm{C}, 5$ days culture & $\mathrm{Zn}$ & Atomic Absorptiometry \\
\hline CODMn & Acid, $100^{\circ} \mathrm{C} \mathrm{KMnO4}$ & $\mathrm{Cd}$ & Atomic Absorptiometry \\
\hline
\end{tabular}

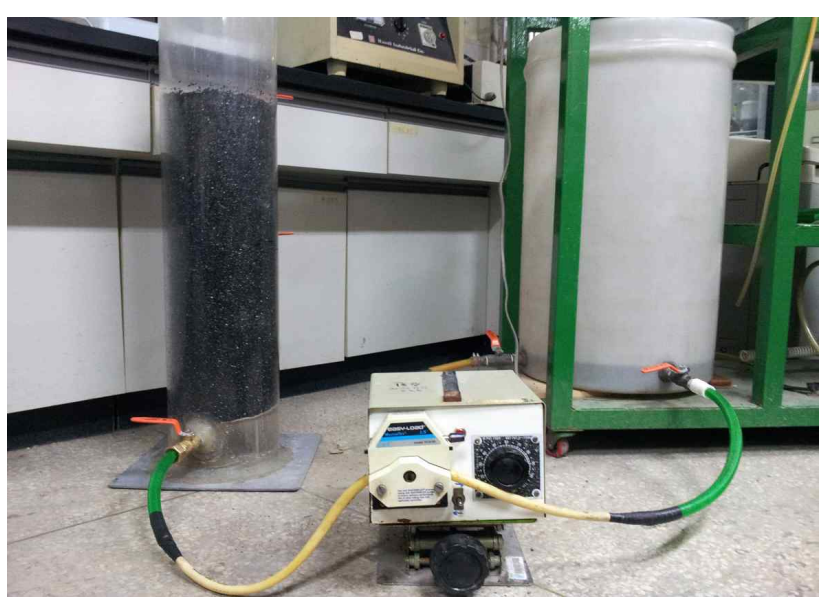

Fig 2. Up-flow type filter is connected to the device through the metering pump and the inlet sample

\section{Results and Discussion}

\subsection{Experiment of Single Filter Media}

To analyze the filtration effect of single filter media, this study measured the level of contamination of the samples first and then the water quality of the samples exposed to the filter media every 20 minutes. It took about 25 minute from when the samples passed the filter media after injected with them to when they generated the first runoff and were collected for purified samples.

\footnotetext{
2) Looking into the values of the two experiments, it can be known that various error and upper and lower limit values were found in the first test due to insufficient preparation for the experiment. Therefore, the stabilized values in the second experiment were adopted since they had certain tendency.
}

Figure 3 shows the maximum filtration effect of all the items to be analyzed from the primary introduction of the filter media to the first runoff. The present study measured the water quality every 20 minutes after the passing time of filter media and examined both maximum absorption and performance consistence of the filter media3).

The results are as follows.

First, the sample water itself had $\mathrm{pH}$ neutral before filtration and there is no change in the value of $\mathrm{pH}$ after filtration.

Second, the $\mathrm{BOD}_{5}$ of the water was removed by about $50 \%$ to $55.6 \%, 63.6 \%, 74.5 \%$ after the filtration with activated carbon, anthracite $(3-5 \mathrm{~mm})$ and vermiculite $(1-3 \mathrm{~mm})$, respectively. However, as times went by, the reduction rates didn't turn out very high. Rather, the level of pollution increased 120 minutes after filtration. The increase can be explained by the increasing runoff of pollution sources absorbed into the filter media. It was shown that Zeolite had the highest reduction rate of $20 \%$ after 120 minutes of its filtration.

Third, COD removal rate by filter media showed that most of the filter media but Zeolite $(5-10 \mathrm{~mm})$ and an activated carbon had about $20 \%$ of decontamination rate in the samples run off right after the filtration. However, the degree of filtration decreased as time passed and some samples filtered by the filter media zeolite $(1-3 \mathrm{~mm}, 5-10 \mathrm{~mm})$ and vermiculite $(1-3 \mathrm{~mm})$ showed rather increasing pollution rate. In general, it turned out that filtration effect of the filter media was mere on COD.

Fourth, filtration effect on SS turned out consistently improving by more than $95 \%$ in the entire filter media until 120 minutes from the beginning of runoff.

Fifth, removal effect on $\mathrm{T}-\mathrm{N}$ turned out improving by $70 \%$ to $80 \%$ in the entire filter media. Among the filter media, zeolite, $(1-3 \mathrm{~mm})$ and vermiculite $(1-3 \mathrm{~mm})$ maintained the effect until 120 minutes from the beginning of runoff while original level of contamination reappeared in the case of activated carbon as time passed on. It verified that activated carbon didn't have consistent filtration effect. On the contrary, vermiculite $(1-3 \mathrm{~mm})$ showed high filtration effect of $80 \%$, followed by zeolite $(1-3 \mathrm{~mm})$ and anthracite with $50 \%$ filtration effect.

Sixth, the filter media didn't have any filtration effect on TP. Rather, pollution level of the water got worse even after filtration by most of the filter media. Among them, zeolite (3-5mm) showed filtration effect of $70 \%$ after runoff and it decreased to $27 \%$ as time moved on.

Seventh, it turned out that all of the filter media reduced $\mathrm{Zn}$ in water by more than $50 \%$ after the initial runoff, but and $\mathrm{Zn}$

3) In general, filter media of installable non-point pollution reduction device has one-year cycle of replacement. And the performance of filter media should be maintained continuously. For this reason, this present experiment measured it every 20 minutes. 
gradually increased from 120 minutes after filtration presumably because the pollution sources stuck to the media set off together with them. Particularly, vermiculite $(1-3 \mathrm{~mm})$ showed more than 90\% filtration effect even 120 minutes filtration, which was the highest removal rate.

Eighth, every filter medium but anthracite showed persistent filter effect on Cd right after runoff and even 120 minutes later (see Cd in Figure 1). Zeolite showed $80 \%$ removal effect on $\mathrm{Cd}$ after filtration vermiculite had more than $90 \%$ removal rate of pollution sources from the water.

\subsection{Experiments with Compound Filter Media}

Based on the results of the experiments with single filter media, a set of two filter media with the highest treatment efficiency were chosen from each item and mixed at one-to-one ratio to make compound filter media. It took about 30 to 35 minute from when the samples passed the filter media and the first runoff was generated to when the purified samples were collected. The measured values by item are shown as follows (see Figure 3).

First, like the results of the experiment with single filter media, $\mathrm{pH}$ value in the purified water didn't change after filtration with the compound filter media. It demonstrates that $\mathrm{pH}$ isn't affected by the compound filter media.

Second, the $\mathrm{BOD}_{5}$ of the purified water reduced up to $16.5-$ $48.5 \%$ after filtration, of which result is similar to that of single filter media. However, the $\mathrm{BOD}_{5}$ of the purified water filtered by the compound filter medium of Zeolite and activated carbon increased by $50 \%$ from 120 minutes after filtration mainly due to the runoff of pollution sources with the water as time passed.

Third, COD also turned out to have reduced a bit after filtration but it started to have original level of pollution as time went by. Therefore, it can be said that the compound filter media don't have filtering effect on COD.

Fourth, filtration effect on SS turned out high by $60 \%$ to $80 \%$ in the compound filter medial of Zeolite + anthracite, zeolite + activated carbon and zeolite + vermiculite 120 minutes after filtration.

Fifth, removal rate of $\mathrm{T}-\mathrm{N}$ turned out to be $70 \%$ to $80 \%$ in Zeolite + anthracite, zeolite + activated carbon and zeolite + vermiculite 120 minutes after filtration. All of the compound filter media showed that they had more than $50 \%$ to $90 \%$ of filtration performance right after filtration and the samples were more purified even 120 minutes after filtration.

Sixth, the filtration effect of the compound filter media didn't appear on TP right after runoff and 120 minutes after.

Seventh, it turned out that all of the compound filter media reduced $\mathrm{Zn}$ and more purified the samples than their original state right to some extent after the initial runoff and even 120 minutes after. Particularly, Compounds with zeolite showed more than $80 \%$ of removal rate of $\mathrm{Zn}$, which answers that it is

Table 3. Removal rate of Water pollution after treatment single filter media (Immediately after spill and after 120 minutes, unit : \%)

\begin{tabular}{|c|c|c|c|c|c|c|c|c|c|c|c|c|c|c|c|c|c|}
\hline & \multicolumn{2}{|c|}{$\mathrm{pH}$} & \multicolumn{2}{|c|}{ BOD } & \multicolumn{2}{|c|}{ COD } & \multicolumn{2}{|c|}{ SS } & \multicolumn{2}{|c|}{$\mathrm{T}-\mathrm{N}$} & \multicolumn{2}{|c|}{ T-P } & \multicolumn{2}{|c|}{$\mathrm{Zn}$} & \multicolumn{2}{|c|}{$\mathrm{Cd}$} & \multirow[b]{2}{*}{ Remarks } \\
\hline & 0 & $\begin{array}{l}\text { after } \\
120\end{array}$ & 0 & $\begin{array}{c}\text { after } \\
120\end{array}$ & 0 & $\begin{array}{c}\text { after } \\
120\end{array}$ & 0 & $\begin{array}{l}\text { after } \\
120\end{array}$ & 0 & $\begin{array}{c}\text { after } \\
120\end{array}$ & 0 & $\begin{array}{c}\text { after } \\
120\end{array}$ & 0 & $\begin{array}{l}\text { after } \\
120\end{array}$ & 0 & $\begin{array}{c}\text { after } \\
120\end{array}$ & \\
\hline $\begin{array}{l}\text { Zeolite } \\
(3-5 \mathrm{~mm})\end{array}$ & - & - & -3.4 & 18.9 & 19.7 & 3.5 & 90.3 & 96.4 & 61.8 & 39.5 & 70.6 & 26.7 & 56.3 & 55.2 & 78.2 & 78.5 & $\begin{array}{c}\mathrm{A} 0 \mathrm{E} \text { in } \mathrm{SS}, \mathrm{T}-\mathrm{N}, \\
\text { T-P, } \mathrm{Zn}, \mathrm{Cd} \\
\mathrm{A} 120 \mathrm{E} \text { in } \mathrm{SS}, \mathrm{Zn}, \mathrm{Cd}\end{array}$ \\
\hline $\begin{array}{c}\text { Zeolite } \\
(5-10 \mathrm{~mm})\end{array}$ & - & - & 9.4 & 1.9 & -19.4 & -16.1 & 78.1 & 93.5 & 66.7 & 52.1 & 4.9 & -15.1 & 44.9 & 36.5 & 44.8 & 54.6 & $\begin{array}{c}\text { Effect in SS, T-N, } \\
\text { Zn, Cd }\end{array}$ \\
\hline $\begin{array}{l}\text { Activated } \\
\text { carbon }\end{array}$ & - & - & 55.6 & -1.5 & 7.3 & -0.4 & 96.1 & 95.9 & 76.1 & 1.2 & -261 & -55.0 & 63.8 & 48.2 & 76.1 & 60.3 & $\begin{array}{c}\mathrm{A} 0 \mathrm{E} \text { in } \mathrm{SS}, \mathrm{T}-\mathrm{N}, \\
\mathrm{Zn}, \mathrm{Cd}\end{array}$ \\
\hline $\begin{array}{c}\text { Anthracite } \\
(1-3 \mathrm{~mm})\end{array}$ & - & - & 33.1 & 10.3 & 21.9 & -0.4 & 95.4 & 97.3 & 70.7 & 50.2 & 23.3 & -8.2 & 54.3 & 39.5 & 53.8 & -14.3 & $\begin{array}{c}\mathrm{A} 0 \mathrm{E} \text { in } \mathrm{SS}, \mathrm{T}-\mathrm{N}, \\
\mathrm{Zn}, \mathrm{Cd}\end{array}$ \\
\hline $\begin{array}{c}\text { vermiculite } \\
(1-3 \mathrm{~mm})\end{array}$ & - & - & 74.5 & 10.5 & 21.1 & -16.7 & 92.9 & 97.4 & 85.6 & 78.4 & 14.9 & -74.6 & 94.1 & 91.7 & 93.9 & 93.9 & $\begin{array}{l}\mathrm{A} 0 \mathrm{E} \text { and } \mathrm{A} 120 \mathrm{E} \text { are } \\
\text { high in all sources } \\
\text { except T-P }\end{array}$ \\
\hline $\begin{array}{c}\text { vermiculite } \\
(3-5 \mathrm{~mm})\end{array}$ & - & - & 30.0 & -15.7 & 26.2 & -0.9 & 93.6 & 95.9 & 75.3 & 33.5 & 17.5 & -7.2 & 31.9 & 25.5 & 40.8 & 37.9 & $\mathrm{~A} 0 \mathrm{E}$ in $\mathrm{SS}, \mathrm{T}-\mathrm{N}$ \\
\hline Remarks & & & $\begin{array}{r}\mathrm{A} 0 \mathrm{E} \\
\text { redi } \\
\mathrm{A} 120 \mathrm{E},\end{array}$ & $\begin{array}{l}0-50 \% \\
\text { tion. } \\
\text { lo effect }\end{array}$ & $\begin{array}{l}\mathrm{A} 0 \mathrm{E} \\
\text { redu } \\
\mathrm{A} 120 \mathrm{E},\end{array}$ & $\begin{array}{l}0-25 \% \\
\text { tion. } \\
\text { to effect }\end{array}$ & $\begin{array}{l}\text { Remo } \\
\text { than } 90 \\
\text { the filt }\end{array}$ & $\begin{array}{l}\text { more } \\
0 \text { in all } \\
\text { media }\end{array}$ & $\begin{array}{r}\mathrm{A} 0 \mathrm{E} 6 \\
\text { reduc } \\
\mathrm{A} 120 \\
\text { Zeoli } \\
\text { vermi }\end{array}$ & $\begin{array}{l}0-80 \% \\
\text { ction. } \\
\mathrm{E}, \text { in } \\
\text { te \& } \\
\text { culite }\end{array}$ & $\begin{array}{r}\text { A0 } \\
\text { Zeolite } \\
\text { and A } \\
3-5 \mathrm{~mm} \\
\mathrm{~A} 120 \mathrm{E} \text {, }\end{array}$ & $\begin{array}{l}\text { of } \\
-5 \mathrm{~mm}) \\
\text { hracite } \\
\text { are high } \\
\text { of effect }\end{array}$ & $\begin{array}{l}\text { A0E } 3 \\
\text { reduc } \\
\text { A120 } \\
\text { const }\end{array}$ & $\begin{array}{l}0-94 \% \\
\text { ction. } \\
\text { E are } \\
\text { tantly }\end{array}$ & $\begin{array}{r}\mathrm{A} 0 \mathrm{E} \\
\text { redu } \\
\mathrm{A} 12 \\
\text { constan } \\
\text { Antl } \\
(1-3 \mathrm{~mm}\end{array}$ & $\begin{array}{l}\text { O-90\% } \\
\text { tion. } \\
\text { are } \\
\text { y(except } \\
\text { acite } \\
3-5 \mathrm{~mm})\end{array}$ & $\begin{array}{c}\text { A0E: Initial } \\
\text { purification effect; } \\
\text { A120E: After } 120 \mathrm{~min} \\
\text { purification effect : }\end{array}$ \\
\hline
\end{tabular}


Analysis to Select Filter Media and The Treatment Effect of Non-point Pollution Source in Road Runoff

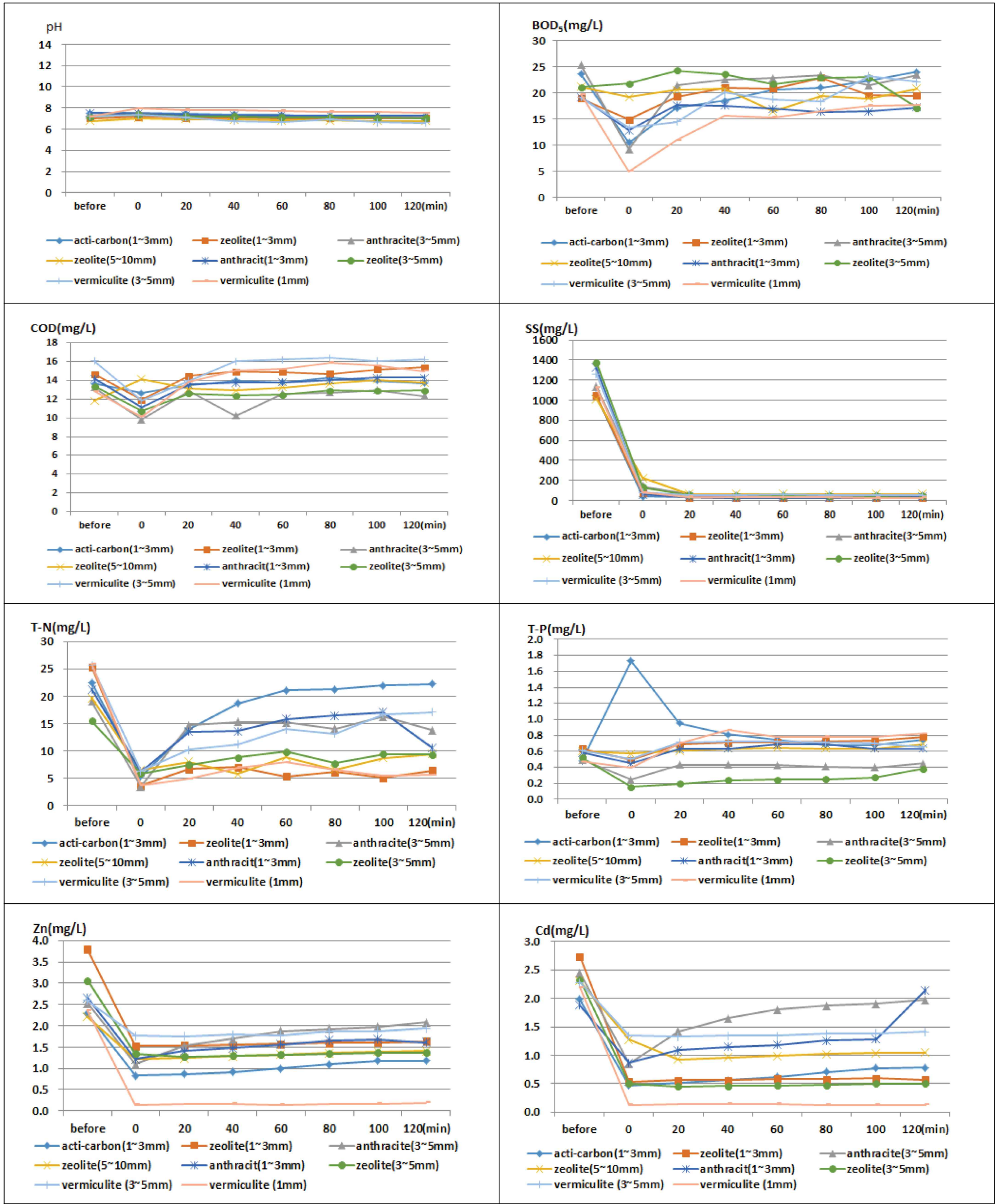

Fig 3. Results of Test on single media

zeolite that removes $\mathrm{Zn}$ rather than anthracite and vermiculite.

Eighth, every compound filter medium showed high removal rate of $\mathrm{Cd}$ and the compounds with Zeolite showed $80 \%$ removal rate. While a single filter medium vermiculite had more than $90 \%$ removal rate of $\mathrm{Cd}$, the compound filter medium of vermiculite and anthracite had relatively weaker purification effect on $\mathrm{Cd}$ 


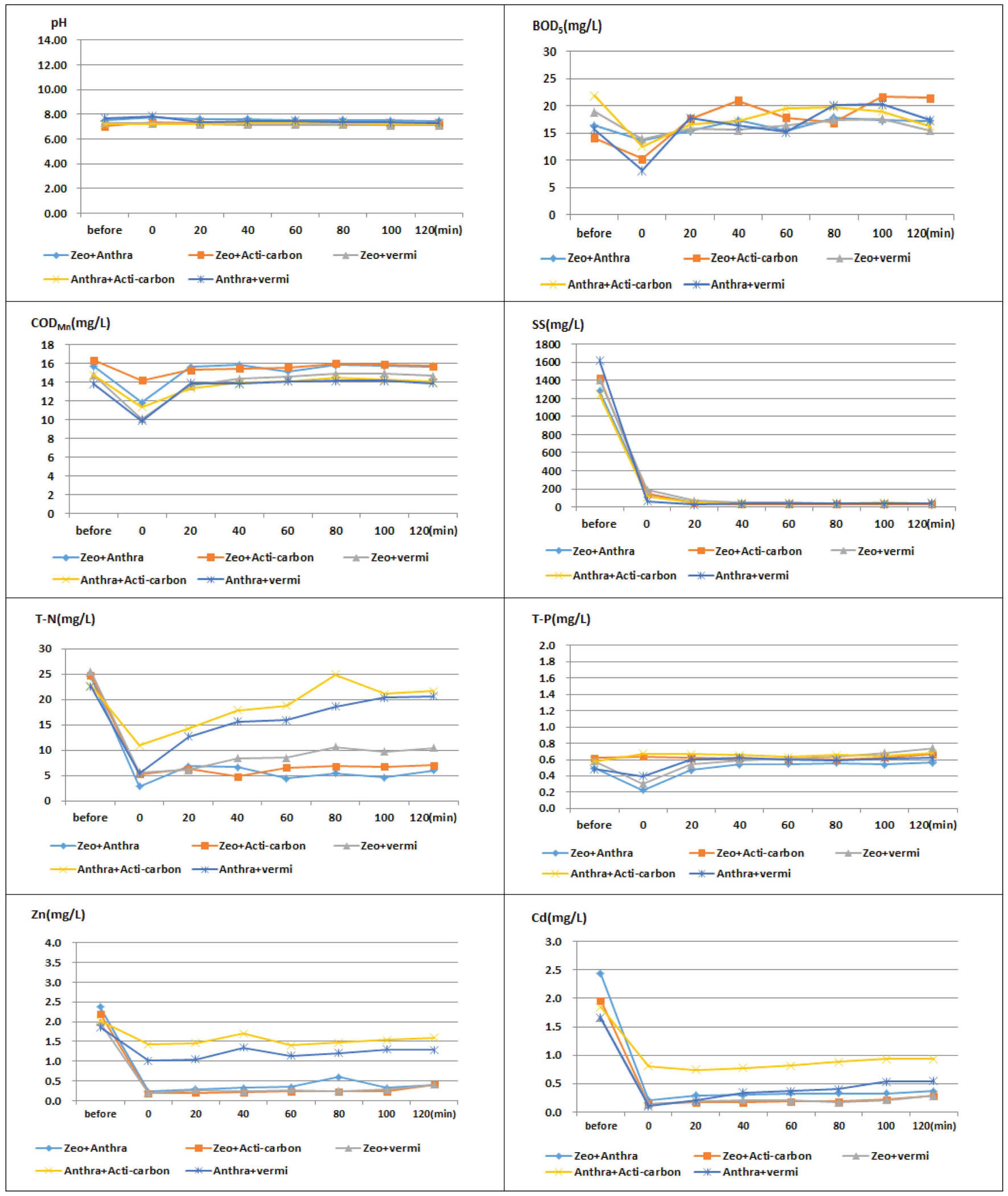

Fig 4. Results of Test on complex media

than other compounds.

In summary, when single filter media are used to reduce non-point pollution sources, it was demonstrated that zeolite and vermiculite are effective in removing SS, TN, $\mathrm{Zn}$ and $\mathrm{Cd}$ while anthracite wasn't effective. In addition, compound filter media are used to reduce non-point pollution sources, it was more effective to mix zeolite as key ingredient with anthracite, activated carbon or vermiculite. 
Analysis to Select Filter Media and The Treatment Effect of Non-point Pollution Source in Road Runoff

Table 4. Removal rate of Water pollution after treatment composite filter media (Immediately after spill and after 120 minutes, unit : \%)

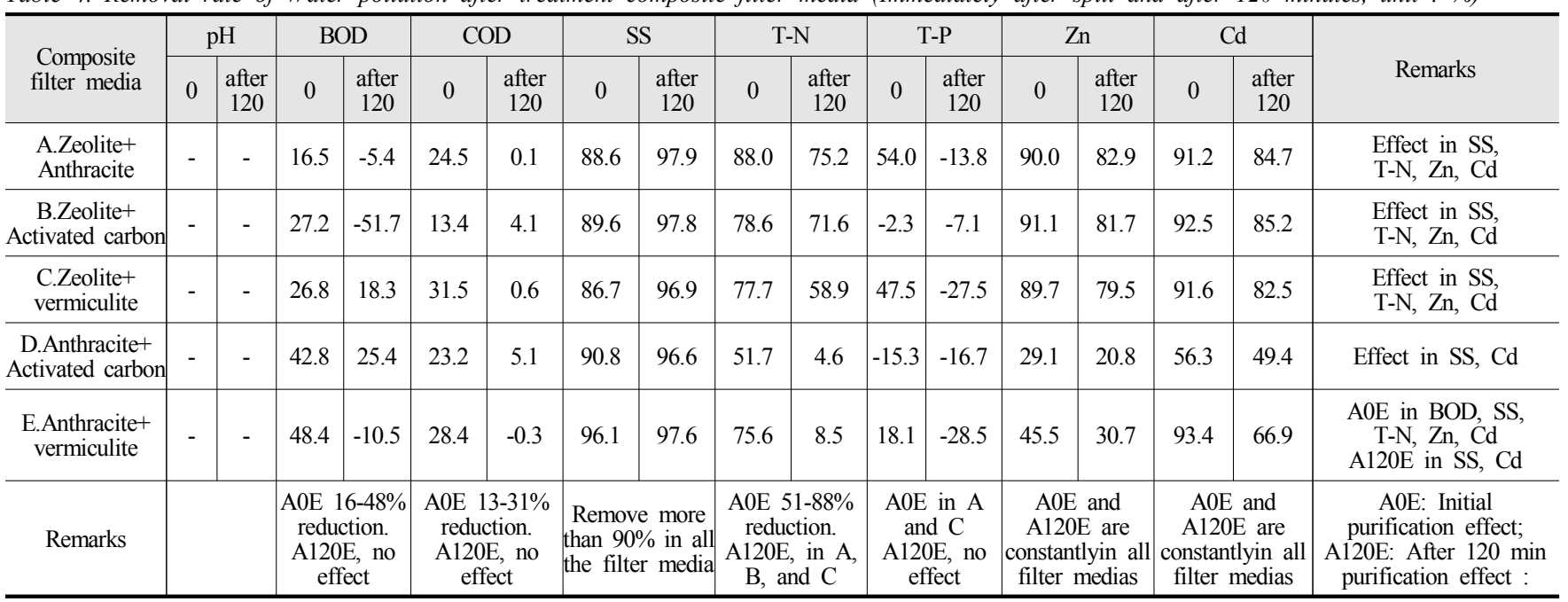

\section{Conclusion}

With the purpose of improving water environment in urban areas, the present study attempted to choose and filter media for non-point pollution reduction device and analyze their effectiveness in order to treat pollution sources in road runoff, which is rapidly generated when rain falls.

First, the factors that have impact on the water quality of runoff exposed to non-point pollution sources are various, including not only physical elements such as land use, type of paved road and the movement of traffic and population, but also the characteristics of rainfall like frequency, intensity and duration of rainfall.

Secondly, this study found out that filter media have maximum filtration effect on every analysis item but $\mathrm{pH}$ from the introduction of filter medium to runoff. And most of the filter media performs persistent filtration effect on SS, TN, Zn and Cd until 120 minutes after it. Unlike the precious studies that focus on the purification performance of filter medium within 30 minutes from the introduction of filter medium to a sample, this study suggested a ground for the determination of the consistent use of filter media.

Third, it turned out in this study that the artificial sample and filter media produced by the source of pollution do not have purification effect on $\mathrm{pH}, \mathrm{BOD}, \mathrm{COD}$ and $\mathrm{T}-\mathrm{P}$. However, they have a very high and consistent effect on SS, TN, Zn and Cd right after filtration and 120 minutes later, respectively.

Fourth, zeolite and vermiculite as single filter medium demonstrated their persistent removal effect on SS, TN, Zn and $\mathrm{Cd}$ while anthracite isn't effective. In addition, when compound filter media are used, it is more effective to mix zeolite as key ingredient with anthracite, activated carbon or vermiculite.
In conclusion, it was learned that it is necessary to consider the characteristics of non-point pollution sources found in road runoff together with those of filter media to be applied to reduce the sources. It is because $\mathrm{COD}_{\mathrm{Cr}}$ and $\mathrm{BOD}_{5}$ among contaminants have higher level of pollution at initial stage but their pollution load decrease as time goes on. Therefore, it is needed to choose filter media that have high filtration effect during initial period for them. That is, it seems plausible to apply the filter media developed in this study to purify $\mathrm{BOD}_{5}$ and $\mathrm{TN}$. On the contrary, TP and SS tend to flow out pollutants continuously on road. Therefore, it is desirable to use filter media with persistent effect of purification for them. To remove SS, it seems effective to use the filter media fabricated in this study.

The results of the present study have demonstrated that it is possible to apply the results to non-point pollution reduction policies and technological fields for urban areas. Therefore, the author expects that the findings of this study will contribute not only to the improvement of urban water environment but also to environment-friendly rainwater management.

\section{Acknowledgements}

This work was supported by the Korea Agency for Infrastructure Technology Advancement grant funded by Ministry of Land, Infrastructure, and Transport.(R\&D/11 Advanced Urban 07).

\section{References}

[1] Go, SH et al. (2009), Characterization of Stormwater Pollutants and Estimation of Unit Loads for Road and Parking Lot in Kyeongan Watershed. Meung-Gi Unvi)

[2] Kim, HJ et al. (2010), A study on design of the retarding basin for reducing non-point source pollution, Honglk Univ) 
[3] Semyung Univ. (2013), A Study on Rainwater Management System to respond to Climate Change in Urban Area. Korea Agency for Infrastructure Technology Advancement.

[4] Son, JW (2009), Nonpoint source pollution monitoring from individual land uses and loading estimate using SWMM model in urban area, Kon-Kuk Univ.

[5] Oh, JI. Park, SW. Choi,YW. (2005), "Characteristics of Non-poin Pollutants from the Road Runoff", Korean Society of Water Quality, Vol.2005. pp.430-435).

[6] Yoon, YS. (2009), A Study on Treatment of First Flush Rainwater using Media, The Graduate School of Industry and Engineering Seoul. National University of Science and Technology.

[7] Lee, YG (2007), Study on the optimum selection of Non-Poin pollutants control facility in the region of Total Water Pollution Load Management. The Univ. Seoul. Dept. Environmental Engineering Graduate School.

[8] Lee, JH (2006), A Study on treatment of first flush rainwater for reducing non-point source pollution, The Univ. Seoul. Dept. Environmental Engineering Graduate School.

[9] Choi, SG (2013), Analysis of Filter-type Facility's Treatment efficiency to Reduce Non-point Pollution Sources, The Graduate School of Industry and Engineering Seoul. National University of Science and Technology.

[10] Hwang, SY (2008), Runoff Characteristics Analysis of Nonpoint Pollution Sources in Small Urban during First Rainfall using Urbanization Runoff Model. The Graduate School of Industry and Engineering Seoul. National University of Science and Technology. 